\title{
Projeto "Monitor de Ecoturismo": Uma proposta de formação continuada e sua relação com a conservação ambiental no município de Resende (RJ)
}

\author{
Project " Ecotourism Monitor" : A proposal of continuing \\ education and its relationship with environmental \\ conservation in the municipality of Resende (RJ, Brazil)
}

\author{
Adriana dos Santos Souza, Karla Beatriz Lopes Baldini
}

\begin{abstract}
RESUMO
Há muito tempo o meio natural tem se tornado uma opção de lazer, sendo o ecoturismo uma base para o desenvolvimento socioeconômico, capaz de proporcionar uma forma de valorização e conservação dos recursos sociais, culturais e naturais com vista a garantir a sustentabilidade da comunidade local onde busca ser desenvolvido. Considerando os diferentes autores e suas abordagens, o presente estudo aborda a temática do ecoturismo e sua relação com a capacitação de monitores locais, sua formação e credenciamento em um município localizado numa região com grande potencial turístico no sul do estado do Rio de Janeiro, bem como sua relação com a conservação da natureza. O objetivo geral do artigo foi sistematizar os dados do projeto realizado pelo município denominado "Monitor de Ecoturismo". Como objetivos específicos, levantar o desenvolvimento do projeto ao longo de suas edições e apresentar a importância das atividades desenvolvidas na capacitação dos monitores locais na manutenção do patrimônio natural do município. Para o desenvolvimento do artigo, os dados foram coletados através de documentos fornecidos pelos órgãos municipais envolvidos, relatos orais de seus colaboradores, releases publicados pelo governo municipal na mídia local e observação direta nas edições do projeto. A partir do material coletado, foi sistematizado como o projeto vem sendo implementado no município ao longo do tempo. Até o presente momento foram realizadas três edições que tiveram duração variada devido alternância da Gestão Municipal e o público-alvo. Foram certificados cerca de 25 monitores em cada edição do curso, com um total de 75 formados. Eles atuam profissionalmente nos atrativos naturais localizados nas Unidades de Conservação e entorno, bem como em eventos esportivos de montanha realizados na região. O curso de formação de "Monitores de Ecoturismo" é estratégico para o desenvolvimento da atividade na região. Sendo continuo, o projeto possibilita, o envolvimento das comunidades locais com a proteção ambiental, através da disseminação do conhecimento das trilhas, geração de renda que o ecoturismo pode proporcionar, já que a demanda por mão-de-obra capacitada é permanente na região.Alem disso, várias trilhas e roteiros ainda precisam ser trabalhados e monitorados de forma permanente. "Conhecer para preservar", esse é um dos princípios do Projeto. Conclui-se que na ausência de planejamento e de capacitação continuada, esse princípio seria impossível de ser alcançado e a conservação ambiental ameaçada.

PALAVRAS-CHAVE: Renda; Associativismo; Atrativos Naturais; Capacitação; Planejamento.
\end{abstract}




\section{ABSTRACT}

A long time ago the natural environment has become a leisure option, and ecotourism a basis for socio-economic development that can provide a form of development and preservation of social, cultural and natural resources to ensure the sustainability of the local community where seeks to be developed. Considering the different authors and their approaches, this study addresses the theme of ecotourism and its relation to the training of local monitors, their training and accreditation in a municipality located in a region with great potential for tourism in the southern state of Rio de Janeiro, as well their relation to nature conservation. The general purpose of the article was to systematize the project data held by the municipality called "Ecotourism Monitor". The specific objectives, raise the development of the project over their issues and present the importance of the activities developed in the training of local monitors in maintaining the natural heritage of the municipality. For the development of the article, the data were collected through documents provided by municipal agencies involved, oral accounts of its employees, releases published by the municipal government in the local media and direct observation in project issues. From the collected material was systematized as the project is being implemented in the city over time. Until now there were three issues that have varying lengths due alternation of Municipal Management and the target audience. They have been certified around 25 monitors in each edition of the course, with a total of 75 graduates. They act professionally in natural attractions located in protected areas and surroundings as well as in mountain sporting events held in the region. The training course "Ecotourism monitors" is strategic for the development of the activity in the region. Being still, the project enables the involvement of local communities to environmental protection, through the dissemination of knowledge of the tracks, generating income that ecotourism can provide, since the demand for hand labor qualified is permanent in the region. In addition, several trails and routes still need to be worked out and monitored permanently. "Knowing to preserve" this is one of the design principles. We conclude that in the absence of planning and ongoing training, this principle would be impossible to be reached and the threatened environmental conservation.

KEYWORDS: Income; Associations; Natural Attractions; Training; Planning.

\section{Introdução}

Nos dias atuais, o turismo é umas das atividades econômicas mais importantes, onde se destaca o segmento do ecoturismo, que por sua vez é uma atividade que tem direta relação com o desenvolvimento sustentável, ele tem interdependência com os setores econômicos, sociais, ambientais e culturais.

Campos (2006) acredita que se o turismo for bem planejado, dentro dos princípios da sustentabilidade, este pode ter um impacto positivo e ser um catalisador de conservação e revitalização de ambientes naturais e culturais.

Há muito tempo o meio natural tem se tornado uma opção de lazer, sendo o ecoturismo ou turismo de natureza uma base para o desenvolvimento socioeconômico, capaz de proporcionar uma forma de valorização e conservação dos recursos sociais, culturais e naturais com vista a garantir a sustentabilidade da comunidade local onde busca ser desenvolvido.

Nas discussões sobre ecoturismo, destacam-se Lindberg e Hawkins (1995), que afirmam que a atividade envolve um compromisso tanto com a natureza (conservação/preservação) quanto com o social (comunidades do 
entorno). Já Brandão e Lopes (1999) descrevem que em sua ideologia mais pura, que o ecoturismo pretende mostrar a natureza ao homem, criando condições de acolhida aos turistas e, ao mesmo tempo favorecendo a geração de renda, e o respeito e preservação do meio ambiente.

Por levar pessoas que têm uma vida urbana com certo tipo de cotidiano, o ecoturismo, de acordo com Neiman (2004) pode constituir-se numa oportunidade boa de transformá-las em defensoras da causa ambiental.

Nas atividades de visitação ao ambiente natural, é fundamental relacionar o planejamento e gestão do ecoturismo com a conservação do ambiente natural que será visitado. Sendo assim, como ressalta Cândido (2003), o trabalho deve prioritariamente visar à questão ambiental e, depois, à econômica.

Há um tempo, afirma Campos (2006) que a demanda do turismo em áreas naturais e selvagens é grande, e continua a crescer porem, os empresários que exploram a atividade nessas áreas, não se preocupam muitas vezes em incluir no planejamento das atividades, a comunidade local. $O$ autor destaca que o ideal seria que as comunidades dos locais "explorados", tivessem participação efetiva no desenvolvimento da atividade. Isso devido na maioria das vezes, haver o perigo da imposição cultural dos turistas que irão frequentar o local das atividades turísticas.

O envolvimento da comunidade local nem sempre é fácil, é necessário formação e capacitação da mão-de-obra. Alguns autores como Santos (2008) ressaltam que todo profissional envolvido com condução de visitantes em áreas naturais, deve estar devidamente treinado, superando o mateiro e a eterna repetição de frases feitas sobre os atrativos turísticos. $O$ ambiente natural possui algumas peculiaridades, como mudança de tempo, presença de animais, obstáculos naturais, entre outros.

Outro autor, Cândido (2003) cita que a capacitação dos recursos humanos é componente essencial para se atingir a conservação ambiental.

Como ressalta Pereira et al. (2015), o papel do monitor se torna evidente e essencial. Uma boa formação garante a base necessária para que o ecoturismo se desenvolva com uma finalidade educativa e ao mesmo tempo contribua para a conservação da localidade. Também possibilita a geração de emprego e renda para jovens e adultos moradores da região, sendo este um dos elementos do turismo sustentável.

Campos (2006) afirma que conseguindo assim, conduzir as pessoas a manterem os ambientes naturais e fortalecer as comunidades receptoras, objetivando a sustentabilidade e conservação de ambos.

Santos (2008), afirma que o constante aperfeiçoamento dos condutores/monitores e o cuidadoso planejamento das atividades devem ser adequados às possibilidades dos atrativos naturais, respeitando os anseios e necessidades do grupo a ser conduzido.

Ribas e Hickenbick (2012) descrevem que no Brasil, a promoção de cursos de capacitação de condutores ambientais locais e 0 seu reconhecimento e regulamentação ainda são incipientes. Contudo, essas 
ações apresentam perspectivas promissoras, especialmente quando se analisa o potencial ecoturístico e a biodiversidade do país.

O Ministério do Meio Ambiente (MMA) recomenda que todos os condutores/monitores e guias devem estar devidamente cadastrados nas Unidades de Conservação (UC) onde atuam. Esses cadastros nas UCs contemplam aqueles que realizam cursos de capacitação e formação para condutores/monitores ou guias reconhecidos pelos órgãos gestores. Por considerar que os mesmos, devem desempenhar um importante papel na experiência do visitante, proporcionando um incremento educativo e interpretativo durante a visita (MMA, 2006).

Em 2008, através da Instrução Normativa 08/2008 do ICMBio (Instituto Chico Mendes de Conservação da Biodiversidade) os condutores de visitantes/monitores ambientais passaram a ser regulamentados em nível federal, a IN estabeleceu normas e procedimentos para a prestação de serviços vinculados à visitação e ao turismo em Unidades de Conservação Federais por condutores/monitores de visitantes. A partir desse instrumento, órgãos públicos estaduais e municipais passaram a vislumbrar a possibilidade de regulamentar a atuação de condutores localmente.

Ferreira e Coutinho (2010) destacam que o condutor ambiental local, apresenta conhecimentos ecológicos vivenciais, específicos da localidade que atua, além de ser um representante ou difusor da cultura local. Além disso, é um agente autorizado por órgãos ambientais para atuar conduzindo visitantes em Unidades de Conservação da Natureza e em outros ambientes naturais protegidos, o que o distingue de qualquer outro profissional da área. Podem ser vistos como uma das vias promotoras do ecodesenvolvimento turístico, em contraposição ao turismo de massa.

Ribas e Hickenbick (2012) descrevem que o condutor/monitor é preferencialmente um integrante do entorno ou da localidade onde atua, um "nativo", apresentando conhecimentos vivenciais do meio biológico e cultural do que interpreta, o que o difere dos demais sujeitos do "mercado" turístico. Sua área geográfica de atuação restringe-se a um atrativo turístico natural específico - como uma Unidade de Conservação (ou seu fragmento) ou mesmo um ecossistema local. Analogicamente, o condutor/monitor pode ser considerado como o especialista da interpretação turística, aquele que conhece profundamente a área que atua, além de utilizar-se de conhecimentos científicos, etnobiológicos e de aspectos culturais locais em suas interpretações, com a promoção de um diálogo de saberes.

As autoras ainda consideram que o condutor/monitor é um promotor da sensibilização ecológica e cultural do visitante, utilizando-se da educação ambiental. Entretanto, deve-se ter em mente - especialmente em cursos de capacitação - que o condutor não é meramente um "professor de campo". Como profissional do eixo turístico, deve preocupar-se com a conservação dos ecossistemas locais, com o bem-estar das populações envolvidas, não se esquecendo do bem-estar e da satisfação dos visitantes. Caso este último aspecto não seja considerado - especialmente quando práticas educativas são empregadas de forma excessiva ou desestimulante, programas ecoturísticos poderão fadar-se ao fracasso. Isso porque o 
visitante não deseja encontrar apenas informações e práticas de sensibilização, mas também momentos de lazer.

O condutor/monitor é fundamentalmente um profissional que conduz pessoas em ambientes naturais protegidos e de interesse paisagístico. Além disso, ele auxilia órgãos ambientais e culturais no monitoramento das áreas que atua, sendo esta ação uma de suas contrapartidas às áreas públicas das quais retira o seu sustento.

Considerando os diferentes autores e suas abordagens, o presente estudo aborda a temática do ecoturismo e sua relação com a capacitação de monitores locais, sua formação e credenciamento em um município localizado numa região com grande potencial turístico no sul do estado do Rio de Janeiro, bem como sua relação com a conservação da natureza.

O objetivo geral do artigo foi sistematizar os dados do projeto realizado pelo município de Resende (RJ) denominado "Monitor de Ecoturismo". Como objetivos específicos, levantar o desenvolvimento do projeto ao longo de suas edições e apresentar a importância das atividades desenvolvidas na capacitação dos monitores locais na manutenção do patrimônio natural do município.

\section{Metodologia}

A metodologia usada no trabalho foi descritiva, com um estudo de caso sobre o Projeto "Monitor de Ecoturismo" realizado no município de Resende (RJ) pelo poder municipal em parceria com instituições locais e voluntárias.

Para o desenvolvimento do artigo, foram usados dados secundários coletados através de documentos fornecidos pelos órgãos municipais envolvidos (Diagnósticos das trilhas do projeto "Monitor de Ecoturismo") e relatos orais de seus colaboradores, releases publicados pelo governo municipal na mídia local e observação direta nas edições do projeto.

A partir do material coletado, foi sistematizado como o projeto vem sendo implementado no município ao longo do tempo.

\section{Área de estudo}

O município de Resende possui uma localização privilegiada, com relevo típico de vale em uma longa planície as margens do Rio Paraíba do Sul que corta toda a sua extensão. Afastando da região de planície, encontra-se um planalto, com leves colinas achatadas. E, mais longe 0 maciço do Itatiaia, que compreende uma escarpa da Serra da Mantiqueira, com o Pico da Agulhas Negras ao fundo (ponto mais alto do estado do Rio de Janeiro) (NIMA/PUC, 2010) (Figura 1). 


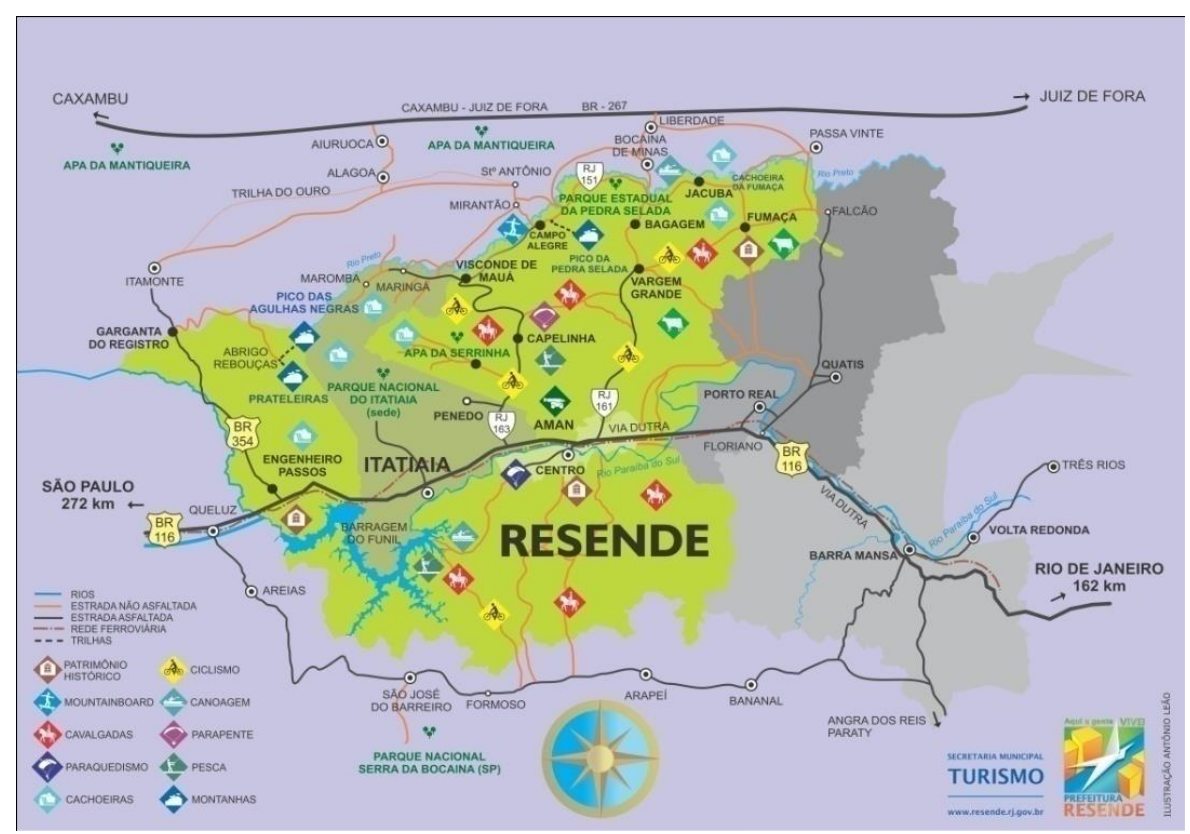

Figura 1: Mapa de localização do município de Resende (RJ) com limites e atrativos. Fonte: Chagas (2015).

Figure 1: Location map of the municipality of Resende (RJ, Brazil) with limits and attractions. Source: Chagas (2015).

A região das Agulhas Negras possui um histórico de vocação para o turismo de aventura e para o ecoturismo, em virtude da beleza dos atrativos naturais emoldurados pelas belas montanhas e importantes rios. Localizada na Serra da Mantiqueira é conhecida nacionalmente pelos clubes de montanhismo e demais praticantes dos esportes de aventura. Juntamente com os municípios de Quatis, Porto Real e Itatiaia, Resende, a "Princesinha do Vale" integra a Região das Agulhas Negras.

O Ministério do Turismo (MT) ressalta a importância da região, como um destino indutor, uma vez que, situada no Vale do Rio Paraíba, a região das Agulhas Negras alia vegetação exuberante, cachoeiras e recantos paradisíacos a um imponente conjunto de formações rochosas (BRASIL,2011).

O município possui uma série de áreas protegidas, administradas por diferentes autarquias (municipal, estadual, federal e privada), como o Parque Nacional do Itatiaia (PNI) que abrange áreas importantes de leste a oeste. Destacam-se ainda na região, as localidades de Visconde de Mauá, Engenheiro Passos e Serrinha do Alambari. Na área cortada pelo Rio Preto, chega-se ao Pico da Pedra Selada, à Jacuba e a Cachoeira da Fumaça (área da APA da Serra da Mantiqueira) (Figura 2).

Além da presença das UC's citadas, o município integra a parcela fluminense do Mosaico Mantiqueira, criado pelo Ministério do Meio Ambiente por meio da Portaria 351 de 11 de dezembro de 2006 (PINHEIRO, 2010). 


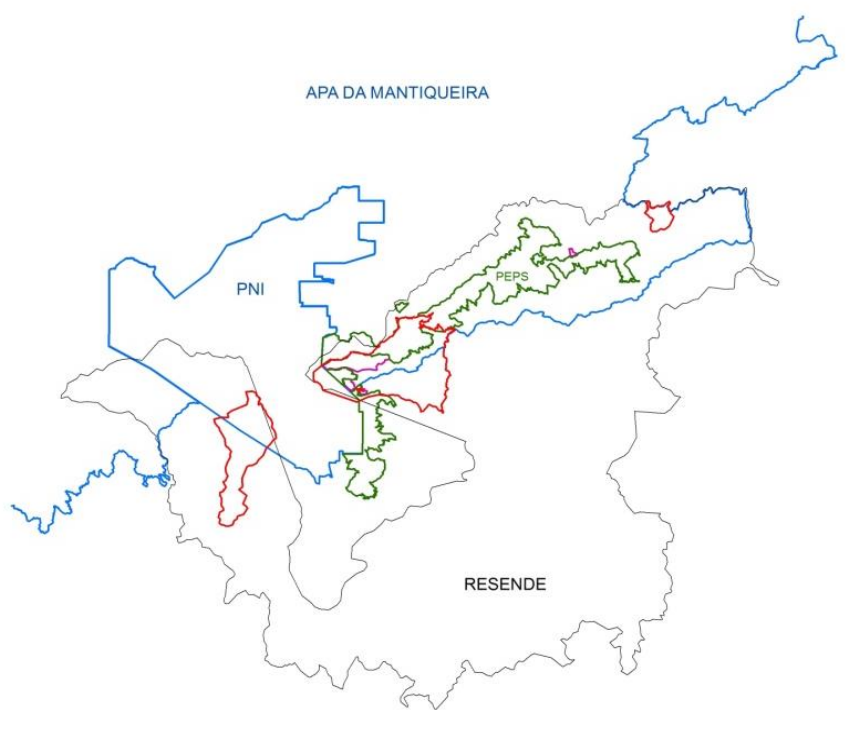

Unidades de Conservação

do município de Resende, RJ

\section{Legenda}

UCs Municipais

UC Estadual

RPPNS

UC Federal

Resende

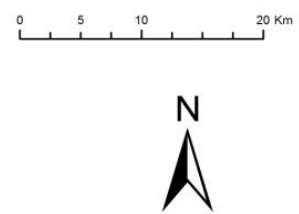

Autor: Baldini, K.B.L. (2015)

Figura 2: Unidades de Conservação localizadas no município de Resende (RJ). Fonte: Baldini (2015).

Figure 2: Protected Areas located in the municipality of Resende (RJ, Brazil).

Source: Baldini (2015).

Santos et al. (2009) ressalta que essas áreas no município, possuem diversas ameaças como atividade agropecuária extensiva com uso de fogo, poluição de rios, a atividade industrial, ocupação irregular, expansão da malha viária, transporte de produtos perigosos e turismo predatório.

De acordo com o diagnóstico (primeira etapa) do projeto "Monitor de Ecoturismo", Resende possui um grande potencial turístico, que, com investimentos no setor, poderá desencadear a geração de emprego e renda para os moradores de áreas com atrativos naturais, impedindo que os mesmos se desloquem para as áreas urbanas, provocando êxodo (AMAR, 2012).

\section{Resultados}

O projeto "Monitor de Ecoturismo", coordenado alternadamente pela AMAR (Agência do Meio Ambiente de Resende) e Secretaria Municipal de Turismo, conta com o apoio do Grupo Excursionista Agulhas Negras (GEAN), Grupamento Ambiental da Guarda Civil Municipal, além de demais instituições como ICMBio - Parque Nacional do Itatiaia/Área de Proteção Ambiental da Serra da Mantiqueira; INEA-RJ/ Parque Estadual da Pedra Selada; MAUATUR - Associação Turística e Comercial da Região de Visconde de Mauá; ONG Crescente Fértil Projetos Ambientais; SEBRAE Resende, entre outras, e voluntários que participaram da elaboração do diagnostico e atuaram como instrutores nas edições do curso.

Até o presente momento foram realizadas três edições que tiveram duração variada devido alternância da Gestão Municipal e o público-alvo. Foram certificados cerca de 25 monitores em cada edição do curso, com um total de 75 monitores formados. 
O desenvolvimento do projeto foi realizado em duas etapas. Primeiramente, realizou vistorias periódicas, pelos servidores envolvidos e voluntários, com o objetivo de produzir dados a partir de anotações de campo, fotos e croquis das trilhas, que serviram como base para relatórios e levantamentos dos atrativos naturais, material para as aulas teóricas e práticas do curso. A atividade exigiu retorno às trilhas em períodos diferentes para comparação dos dados, por exemplo: alta e baixa temporada; finais de semana comuns e feriados; estações chuvosas e secas. Resultando no "Diagnóstico dos Atrativos Naturais do município de Resende, RJ".

Em sua segunda etapa depois dos levantamentos e diagnósticos, o projeto "Monitor de Ecoturismo" ofereceu um curso de capacitação gratuito, visando à formação de Monitores de acordo com os princípios do excursionismo de mínimo impacto e da IN 08/2008 do ICMBIO. Foram selecionados jovens a partir de 18 anos entre as comunidades locais de Resende para participarem da capacitação.

Após a conclusão do curso, os alunos que obtiveram desempenho acima da média nas avaliações e $70 \%$ de frequência receberam Certificado de Conclusão e uma carteira de identificação para exerceram a atividade de monitores expedida pela Secretaria Municipal de Turismo.

\section{Histórico das edições do projeto}

Na sua primeira edição ocorrida no ano de 2004, o público alvo foi selecionado a partir de três grupos: um projeto realizado pela Prefeitura Municipal denominado "Guia Mirins", estudantes do Curso Técnico de Turismo do Colégio Municipal Getúlio Vargas e servidores municipais. $O$ curso teve a duração de um ano, com carga horária de 115 horas com aulas práticas e teóricas. $\mathrm{Na}$ época, atendeu preferencialmente moradores da área urbana (CHAGAS, 2001).

Nesta primeira edição, com base nos levantamentos realizados, o projeto produziu material educativo sobre a Área de Proteção Ambiental Municipal da Serrinha do Alambari (APASA): um CD-ROM com a maquete virtual, um folheto para os visitantes e conjunto de placas educativas instaladas na área, e ainda um vídeo apresentando alguns dos atrativos naturais de Resende. A produção deste material foi realizada através dos convênios IBAMA - PMR: 041/2001 (APA da Mantiqueira) e 042/2001 (APA da Serrinha), que também possibilitaram a aquisição de três veículos para a então Secretaria Municipal do Meio Ambiente (CHAGAS, 2004).

Além desses produtos, em parceria com a Associação FinlândiaBrasil, o projeto trabalhou na recuperação da trilha da Pedra Selada (Figura 3).

O projeto foi interrompido em janeiro de 2005 e reativado em 2010 . Em 2011, foi lançado o Folder Comemorativo pelos "20 anos da APA da Serrinha" e ao longo de mais de dois anos de trabalho, foram realizados levantamentos em 35 trilhas em Resende (RJ) totalizando $76.994 \mathrm{~m}$ (aproximadamente $77 \mathrm{~km}$ ) de trilhas percorridas e monitoradas pela equipe (levando-se em consideração o percurso de ida e volta). 

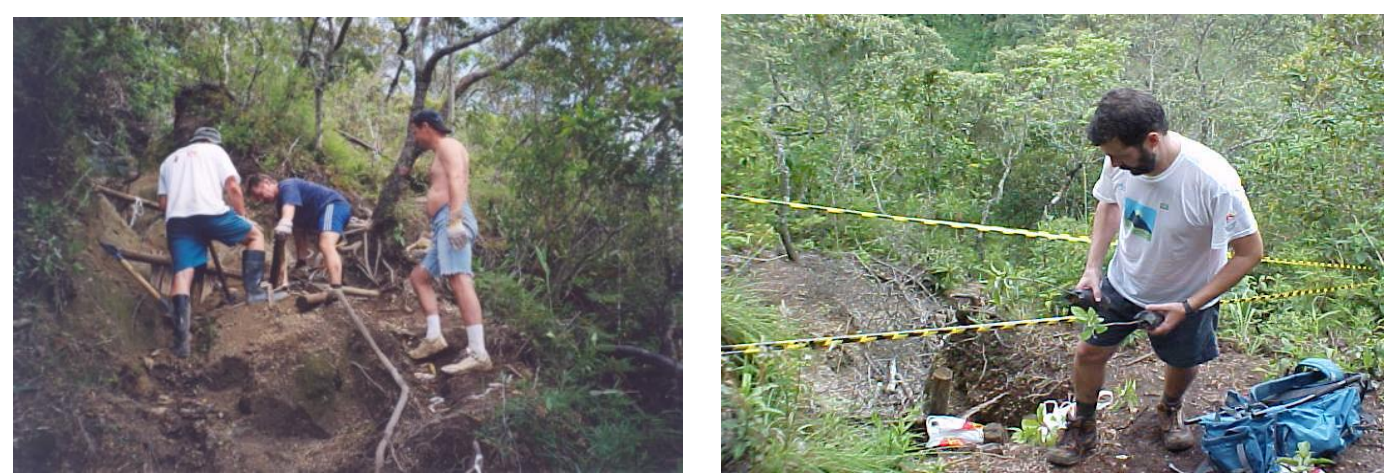

Figura 3: Recuperação da Trilha da Pedra Selada realizada pelo Projeto.

Fonte: Chagas (2004).

Figure 3: Recovery Trail Pedra Selada performed by the Project. Source: Chagas (2004).

Depois de muito dado coletado e sistematizado sobre o município. A segunda edição aconteceu no ano de 2013 na APA da Serrinha do Alambari (APASA) com duração de três meses e carga horária de 70 horas. Já a terceira edição, no ano de 2014 aconteceu na região de Visconde de Mauá, com duração de quatro meses e carga horária de 120 horas.

As aulas teóricas foram ministradas na Escola Municipal Moacir Coelho da Silveira (Serrinha do Alambari) e no Salão Comunitário da Igreja de São Lourenço (Lote 10 - Visconde de Mauá) (Figura 4).
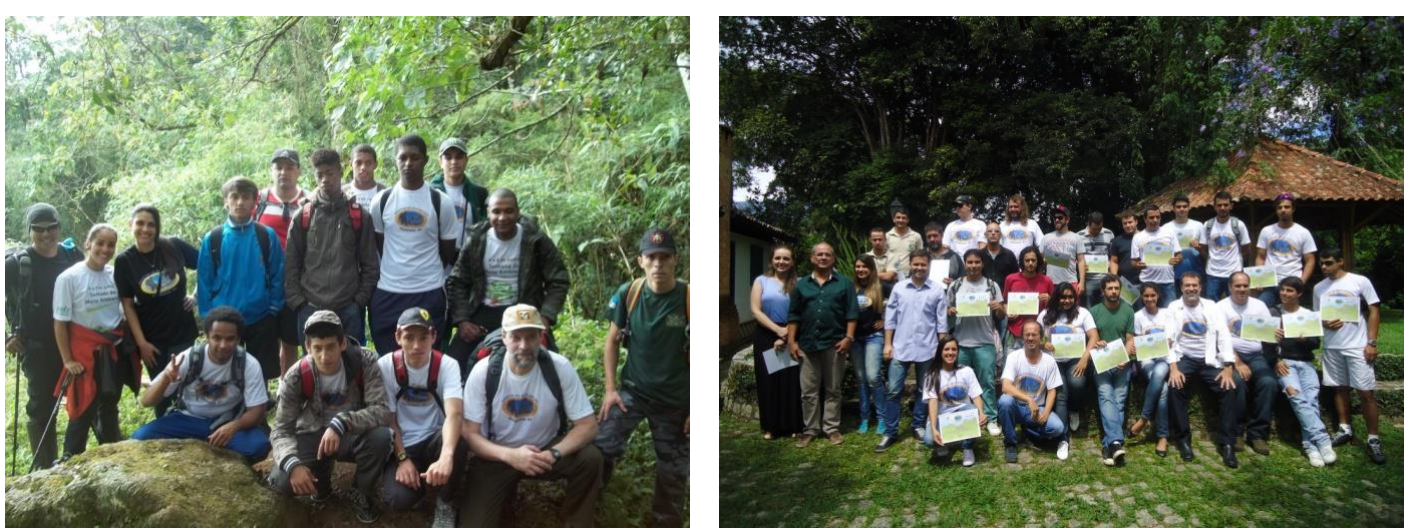

Figura 4: Turmas formadas pelo projeto (2013 e 2014). Fonte: Chagas $(2013,2014)$.

Figure 4: Classes formed by the project ( 2013 and 2014$)$. Source: Chagas $(2013,2014)$.

As três edições incluíram aulas teóricas nas quais os alunos, receberam noções de Montanhismo, Preparação para Caminhadas, História e Geografia Regional, Unidades de Conservação Locais e Mosaico Mantiqueira, Orientação e Navegação, Legislação Ambiental, Empreendedorismo, Turismo, Primeiros Socorros, Fauna e Flora Locais, entre outros. Já as aulas práticas, foram realizadas nos principais atrativos da região, através de excursões na Pedra Selada, Cachoeiras do Santuário, Pedra da Boca do Sapo e Pedra da Gávea (Região de Visconde de Mauá); em trilhas da APA da Serrinha do Alambari e no Planalto do Parque Nacional do Itatiaia como Morro do Couto, Pedra do Altar e Prateleiras.

Nas duas últimas edições, optou-se por selecionar alunos que fossem moradores das localidades onde o curso foi realizado. A escolha ocorreu por eles conhecerem a região e algumas trilhas, facilitando e enriquecendo a capacitação, uma vez que trouxeram novas trilhas, antes desconhecidas pela equipe técnica do projeto. 
A turma formada em 2013 atua na Área de Proteção Ambiental da Serrinha do Alambari. Após o curso, os monitores formados organizaram um Grupo Excursionista denominado GESA (Grupo Excursionista da Serrinha do Alambari). Atualmente, realizam passeios monitorados, auxiliam no mapeamento das trilhas e atividades educativas nos períodos de alta temporada e feriados. O grupo divulga suas ações por redes sociais e tem logomarca própria. Eles possuem autorização de alguns proprietários para acessar atrativos em áreas particulares na localidade.

Já os monitores formados em Visconde de Mauá (2014), atuam no Parque Estadual da Pedra Selada e algumas áreas na APA da Serra da Mantiqueira. Esse grupo organiza uma associação chamada "Pé na Trilha Visconde de Mauá". Divulga suas ações por redes sociais (possuem uma home Page), e atualmente busca uma sede própria.

A organização dos grupos e associações partiu da vontade dos próprios monitores formados pelo curso pela possibilidade observada ao longo do curso de capacitação.

Nos anos de 2013-2015, os monitores formados tiveram a oportunidade de atuar em eventos esportivos de montanha auxiliando nas provas e competidores, que aconteceram na região das Agulhas Negras como o Desafio das Serras/Adventure Camp (2013), Mountain Do/Circuito de Charme - Etapa Carioca (2014) e Endurance Challenger - Ultra Trail Agulhas Negras/TRC (2015).

Como produto da terceira edição, a Secretaria de Turismo de Resende e a AMAR, em parceria com a Assessoria de Comunicação da Prefeitura, produziram o Guia do Visitante de Visconde de Mauá, com o objetivo de prestar informações turísticas e orientar os visitantes sobre as normas da Área de Proteção Ambiental (APA) da Serra da Mantiqueira (Tabela 1).

Tabela 1: Ações e resultados diretos do Projeto "Monitor de Ecoturismo", Resende (RJ).

Table 1: Actions and direct results of the Project " Ecotourism Monitor ", Resende (RJ, Brazil).

\begin{tabular}{|c|c|c|}
\hline Necessidade & Ação & Ano \\
\hline \multirow{6}{*}{$\begin{array}{c}\text { Acesso às trilhas (abertura, limpeza } \\
\text { e manutenção) }\end{array}$} & Pedra Selada & 2004 \\
\hline & $\begin{array}{lll}\text { Travessia } & \text { Serrinha-Penedo } & \text { (Via } \\
\text { Celestino) } & & \\
\end{array}$ & 2013 \\
\hline & Pedra da Boca do Sapo & $2012-2015$ \\
\hline & Pedra do Sabão & $2012-2015$ \\
\hline & Pedra da Gávea & $2012-2015$ \\
\hline & Cruzeiro & $2012-2015$ \\
\hline Mapeamento das trilhas & & $2012-2015$ \\
\hline $\begin{array}{l}\text { Banco de dados dos atrativos do } \\
\text { município }\end{array}$ & Diagnóstico do monitor & $2001-2015$ \\
\hline $\begin{array}{c}\text { Maior presença institucional nas } \\
\text { áreas turísticas }\end{array}$ & $\begin{array}{l}\text { Aumento da atuação do município (ações } \\
\text { de monitoramento permanentes) }\end{array}$ & $2001-2015$ \\
\hline $\begin{array}{c}\text { Capacitação de mão-de-obra para } \\
\text { o turismo local }\end{array}$ & 75 monitores formados & $\begin{array}{l}2004 \\
2013-2014 \\
\end{array}$ \\
\hline \multirow{2}{*}{ Associações de turismo locais } & GESA (Serrinha do Alambari) & 2013 \\
\hline & Pé na Trilha (Visconde de Mauá) & 2014 \\
\hline \multirow{5}{*}{$\begin{array}{l}\text { Material de divulgação dos } \\
\text { atrativos }\end{array}$} & Guia do visitante (Serrinha do Alambari) & $2001-2014$ \\
\hline & Maquete virtual da Serrinha do Alambari & 2001 \\
\hline & Video educativo Serrinha do Alambari & 2001 \\
\hline & Folder dos 20 anos da APASA & 2011 \\
\hline & Guias do Visitante (Visconde de Mauá) & $2014-2015$ \\
\hline Mapeamento das trilhas & & $2012-2015$ \\
\hline Sinalização dos atrativos & $\begin{array}{l}\text { Placas educativas na Serrinha do } \\
\text { Alambari }\end{array}$ & 2001 \\
\hline
\end{tabular}




\section{Considerações finais}

Há muitos desafios a serem enfrentados pelo Brasil no que dizem respeito à conciliação da proteção de ecossistemas ricos em biodiversidade e sua exploração econômica, principalmente por atividades turísticas (MEDEIROS; ARAUJO, 2011). A partir do surgimento do conceito de Ecoturismo percebe-se não somente sua importância econômica, mas acima de tudo a busca pela melhoria da qualidade ambiental incluindo as populações das localidades envolvidas atingindo dessa forma resultados significativos e positivos no desenvolvimento da atividade.

Espera-se que sejam elaboradas políticas públicas voltadas à promoção do ecoturismo, que legitime a capacitação de condutores ambientais locais, e que seja uma estratégia capaz de promover efetivamente um turismo social e ambientalmente responsável.

O curso de formação de "Monitores de Ecoturismo" é estratégico para o desenvolvimento da atividade no município. Resende possui muitas áreas protegidas, constituídas por Unidades de Conservação de diferentes autarquias e categorias (federal, estadual, municipal e particular), muitas apresentam difícil acesso, encontram-se em áreas particulares, falta de sinalização adequada e pouca frequência da fiscalização ambiental. Dessa forma, propicia o turismo predatório, irresponsável, que pode acarretar grandes desequilíbrios ambientais no local e nas suas trilhas de acesso como incêndios florestais e descarte inadequado de resíduos.

O "Projeto Monitor de Ecoturismo" representa uma alternativa para auxiliar nessa questão, uma vez que alia o monitoramento ambiental, aumentando a presença institucional, ao turismo monitorado através dos jovens capacitados para atuar nas referidas áreas. Possibilita assim, 0 envolvimento das comunidades locais com a proteção ambiental, através da disseminação do conhecimento das trilhas e também da geração de renda que o ecoturismo pode proporcionar.

Há carência de profissionais capacitados para orientar e conduzir os visitantes na Região das Agulhas Negras, e cabe ao monitor desempenhar este papel. Guia e condutor não devem ser vistos como concorrentes, mas como profissionais que se complementam e que diversificam roteiros turísticos (FERREIRA; COUTINHO, 2010). Além da demanda da cadeia produtiva do turismo, há grande interesse da população local na atividade.

O projeto é continuo, já que a demanda por mão-de-obra capacitada é permanente na região. Está prevista uma edição para o ano de 2015. Essa etapa, atualmente é coordenada pela Secretaria Municipal de Turismo. As trilhas que farão parte do componente curricular das aulas práticas serão as mesmas localizadas nas Unidades de Conservação e ou no entorno, conforme aconteceram nas edições anteriores.

Além dos folders já publicados e distribuídos para a população, também está previsto a elaboração de um "Guia das trilhas de Resende" e, finalmente, realizar as atividades de reciclagem para complementação da formação dos monitores das edições passadas.

Além disso, várias trilhas e roteiros ainda precisam ser trabalhados e monitorados de forma permanente. "Conhecer para preservar", esse é um 
dos princípios do Projeto "Monitor de Ecoturismo". Conclui-se verificando que, na ausência de planejamento e de capacitação continuada, esse princípio seria impossível de ser alcançado e a conservação ambiental ameaçada.

\section{Referências Bibliográficas}

AMAR (Agência do Meio Ambiente do Município de Resende). Diagnóstico das trilhas (parte 1 e 2): Monitor de Ecoturismo. PMR-AMAR. Resende, 2012.

BRANDÃO, N.L.M.C.; LOPES, S.S. Ecologia e Meio Ambiente - mais de mil conceitos. Fundação Educacional Rosemar Pimentel. 265 p. Volta Redonda.1999.

BRASIL. Diretrizes para a visitação em Unidades de Conservação. Ministério do Meio Ambiente. 72 p. 2007.

BRASIL. Roteiros do Brasil. Ministério do Turismo. Governo Federal. 2011. CAMPOS, A.M.N. Turismo: a relação do ecoturismo e das trilhas interpretativas. Revista Espaço Acadêmico. №57, fevereiro, 2006

CANDIDO, L.A. Turismo em áreas naturais protegidas. Editora EDUCS, Caxias do Sul. 303 p. 2003

CHAGAS, A.A.L. Projeto Monitor de Ecoturismo. Prefeitura Municipal de Resende, 2001.

CHAGAS, A.A.L. Relatório Final do Projeto Monitor de Ecoturismo. Prefeitura Municipal de Resende, 2004.

FERREIRA, L.F.; COUTINHO, M.C.B. Ecoturismo: A Importância da Capacitação Profissional do Condutor Ambiental Local. In: Gestão Ambiental e Sustentabilidade no Turismo. Barueri, SP: Manole, 2010, p. 349-381.

LINDBERG, K.; HAWKINS, D.E. Ecoturismo: um guia para planejamento e gestão. São Paulo:Senac. 1995.

MEDEIROS, R.; ARAUJO, F. F. Dez anos do Sistema Nacional de Unidades de Conservação da Natureza: Lições do passado, realizações presentes e perspectivas para o futuro. Brasília. MMA. 2011

NEIMAN, Z. Ecoturismo em unidades de conservação como estratégia para a educação ambiental. Anais do II Encontro da ANPPAS. Maio de 2004. Indaiatuba, São Paulo, Brasil.

NIMA/PUC. Educação Ambiental: Formação de valores ético-ambientais para o exercício da cidadania do município de Resende/Visconde de Mauá. Núcleo Interdisciplinar de Meio Ambiente (NIMA/PUC). Petrobras, PMR, PUC-RJ. 192 p. 2010 
PEREIRA, A.I.A.; SILVA, F.J. L.; SILVA-JUNIOR, J.M. Influência dos cursos de capacitação do Projeto Golfinho Rotador na atuação profissional dos condutores de ecoturismo em Fernando de Noronha (PE): uma contribuição a sustentabilidade turística local. Revista Brasileira de Ecoturismo, São Paulo, v.8, n.1, fev/abr2015, pp.31-58.

PINHEIRO, M.R. Recomendações para reconhecimento e implementação de mosaicos de áreas protegidas. Brasília, DF. GTZ, 2010.

SANTOS, R.P. Condução de visitantes em Unidades de Conservação. In: Gestão de Unidades de Conservação e Educação Ambiental. Volume 1. Secretaria de Meio Ambiente do Governo do Estado de São Paulo. 116 p. 2008.

SANTOS, M. A. ET AL. REGIÃO INDUSTRIAL DO MÉDIO PARAÍBA. IN: BERGALLO, H. G Estratégias e ações para a conservação da biodiversidade no estado do Rio de Janeiro. 344 p. Rio de Janeiro. Instituto Biomas.

\section{Agradecimentos}

Antônio Leão (Idealizador/criador do projeto "Monitor de Ecoturismo", Coordenador da primeira edição e atual Secretário de Turismo - PMR), Agenor Maia de Siqueira (Atual Coordenador do Projeto "Monitor de Ecoturismo"), Wilson Oliveira Ribeiro de Moura (Secretario do Municipal do Meio Ambiente durante a primeira edição do curso e Atual Presidente da AMAR), Monitores de Ecoturismo de Resende das turmas de 2004, 2013 e 2014 e demais parceiros e colaboradores voluntários.

Adriana dos Santos Souza: Agência do Meio Ambiente do Município de Resende, Resende, RJ, Brasil.

E-mail: adriana.amar@yahoo.com.br.

Link para o currículo Lattes: http://lattes.cnpq.br/5673272520725915

Karla Beatriz Lopes Baldini: Universidade Federal Rural do Rio de Janeiro, Rio de Janeiro, RJ, Brasil.

E-mail: beatriz.karla@gmail.com.

Link para o currículo Lattes: http://lattes.cnpq.br/58381367234477652

Data de submissão: 24 de abril de 2015

Data de recebimento de correções: 17 de agosto de 2015

Data do aceite: 17 de agosto de 2015

Avaliado anonimamente 